\title{
Conservation of plants on Mulanje Mountain Malawi
}

\section{Ian Edwards}

Mulanje massif in Malawi rises steeply from the surrounding plain, a landmark for miles around. An endemic cycad grows on its slopes and the plateau grassland is rich in endemic plants, including everlasting flowers and a heath. The mountain is also the stronghold of the Mulanje cedar, which Malawi has just declared as its national tree. The author, who prepared a report for the Malawi Government on cedar resources on Mulanje, found that the Forestry Department's fire control programme is effective, and that attention now needs to be given to the threat from alien plant invasion.

Mulanje massif, in the south of Malawi, is the highest mountain in Central Africa, the main peak, Sapitwa, reaching almost $3000 \mathrm{~m}$. The massif rises steeply from the surrounding Phalombe plain so that viewed from a distance it resembles a precipitous island. From a botanical point of view this analogy is a good one; the climate of the high plateaux is so dissimilar to that of the plain that the two zones have a totally different flora. The plants on Mulanje are as isolated as those on an oceanic island surrounded by salt water.

Of course the vegetation on Mulanje shows close affinities with other mountains in the Afromontane archipelago, which stretches from Ethiopia to the Cape, and certain widespread

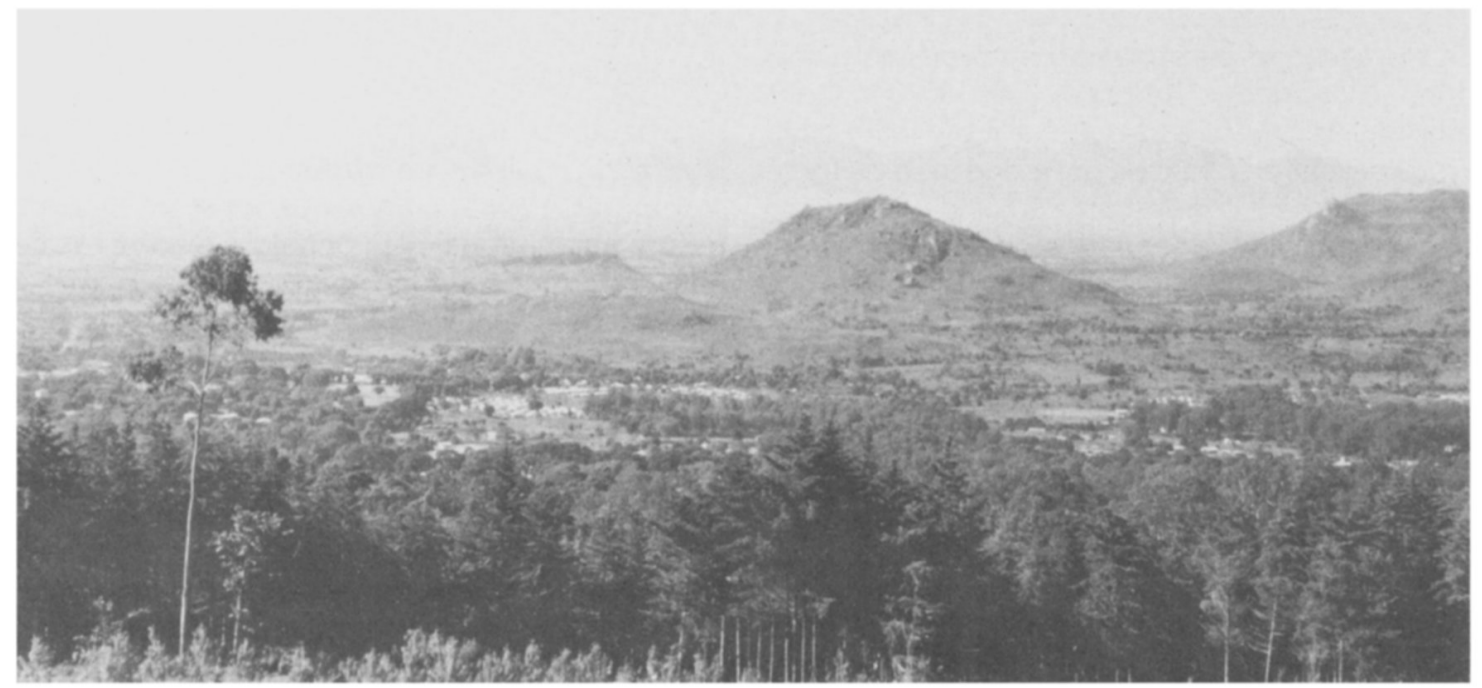

Mulanje massif viewed from Zomba, $70 \mathrm{~km}$ away (Ian Edwards). 
species, such as the curry bush Hypericum revolutum and bitter almond Prunus africana, occur on highlands throughout Africa. However, climatic isolation over a long period has resulted in the evolution of plants especially adapted to the peculiar environmental conditions found on Mulanje. Wild (1964) listed 30 plants found only on Mulanje and while this list needs updating the total number of endemic species is probably around this figure. Thus it is not an exaggeration to describe the flora of Mulanje as unique.

\section{The lower slopes}

One of the first plants encountered when ascending Mulanje from the Forest Station at Likhubula is the cycad, Encephalartos gratus. This is restricted to stream banks around the foot of Mulanje and of neighbouring Milanje Mountain in Mozambique. Although it appears safe, at least for the present, in its stronghold along the Likhubula River, further east, encroachment within the forest reserve has left isolated cycads standing in cultivated gardens. It is impossible to say how long they might survive under these conditions, but as all the deciduous trees around them have been ring-barked it is hard to imagine these evergreen relics will be tolerated for long.

The steep gradient and high rainfall experienced on the southern slopes makes them highly unsuitable for growing crops, but a critical shortage of land and a rapidly expanding population has resulted in desperate attempts to cultivate these eroding soils. Most of the encroachment has been at the expense of tall, semi-deciduous woodland but in places it has extended further up the slopes into sub-montane rain forest and into the evergreen gallery forests which border the streams coming off the mountain. These forests are critical for water supply and already the effects of deforestation are being felt over an increasingly large area as piped water systems begin to silt up.

\section{The grasslands}

The Mulanje cycad occurs at altitudes as low as $850 \mathrm{~m}$, but most of the endemic plants are restricted to areas above $1900 \mathrm{~m}$. At this level there are a number of dissected plateaux and shelves, covered in rolling grassland, with forest patches in sheltered hollows and valleys. Most of Plant conservation in Malawi the grassland is secondary, having been derived by fire from the formerly more extensive forest. There are eye witness accounts from the 1890s of the destruction caused by uncontrolled fires, which originated in villages on the plain, climbed the sides of the mountain by leaping between tufts of sedge and swept across the grassy plateaux eating into the relic forest patches (Carruthers, 1894).

Fire protection measures were introduced from about 1901 to safeguard the remaining forest and the proportion of grassland has changed little during this century. The original policy was to burn all the grasslands deliberately early in the dry season. Although this practice protected forest patches from more serious fires, which might otherwise occur later in the dry season, it also prevented many grassland herbs from flowering and eliminated regeneration of woody species. From about 1950 the Forestry Department constructed a system of firebreaks with the aim of completely protecting the plateaux. The result was a thickening of the grass layer and the gradual re-invasion of woody shrubs (Chapman, 1962). A further outcome, in some areas, was spectacular mass flowering of everlasting sunflowers (Helichrysum spp.) in early summer.

Although the plateaux grasslands are largely the result of man-made fires they support a surprisingly rich flora, including a number of endemic species and a variety of terrestrial orchids. The explanation for this paradox is believed to lie in the rocky slopes above $2100 \mathrm{~m}$. The soil in the grassy hollows between boulders is very shallow and it is unlikely that these exposed areas ever supported forest. Consequently they must always have provided a habitat for herbaceous plants, which were in an ideal position to colonise the lower plateaux as forest gave way to grassland. A number of endemic species, including the beautiful pink everlasting Helichrysum whyteanum, the semi-succulent labiate Plectranthus crassus, and the heath Erica milanjiana, probably evolved in these natural rock gardens and continue to be found there.

The status of plants within these rocky refuges has not been investigated, but they are probably among the most secure habitats on the massif. The broken nature of the ground helps protect 


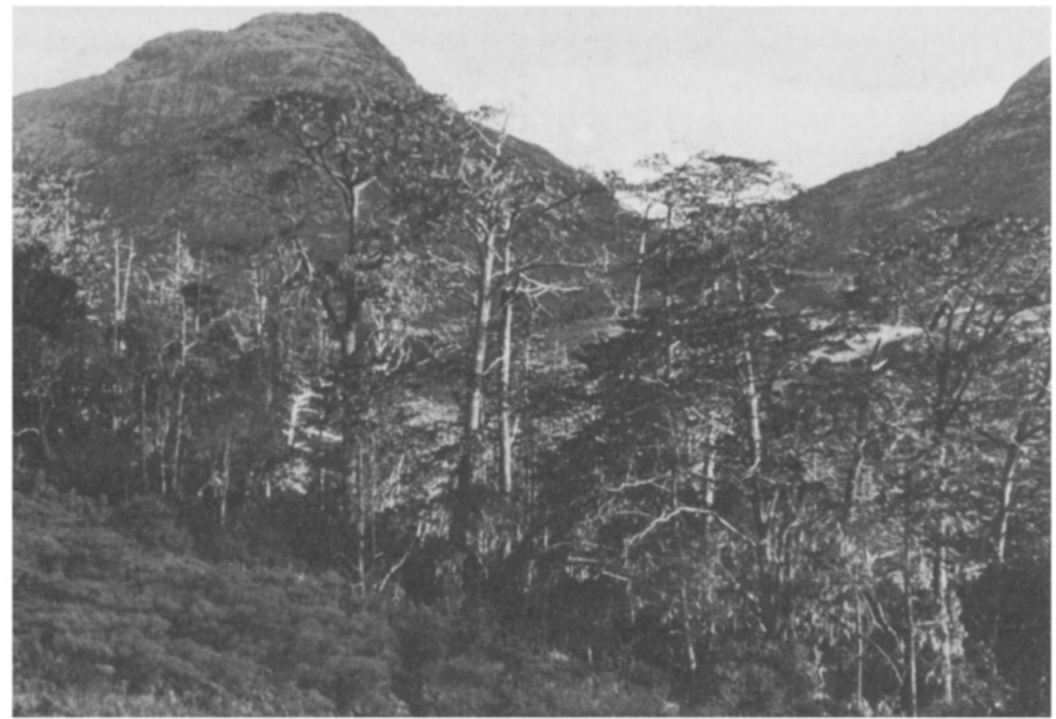

Left: Mature stand of Mulanje cedar (Ian Edwards).

Below: Mulanje cedar (Ian Edwards).

the grassy patches from accidental fires, which occasionally burn large areas of the lower plateaux. Visitors are asked to refrain from picking the attractive Helichrysum whyteanum flowers (Eastwood, 1979), but in any case this activity cannot be regarded as a serious threat to the survival of this species, which is often found on inaccessible ledges. At present these rich areas appear fairly safe, but plants within the other important habitat for endemics, forest glades and margins, are in a less fortunate position.

\section{Montane forest}

Much of the montane forest, especially on the drier northern plateaux, is dominated by the conifer Widdringtonia nodiflora, commonly known as Mulanje cedar. It is not endemic, but it is only on Mulanje, at the northern limit of its natural range, that large trees over $40 \mathrm{~m}$ tall are found. Elsewhere in central and southern Africa it rarely exceeds $15 \mathrm{~m}$ in height. Mulanje cedar yields a valuable fragrant timber, which is exceptionally durable, remaining usable long after the tree has died. The cedar stands have been exploited for over 80 years and all the larger stands have been cut-over in the past (Chapman, 1961). The Forestry Department issues licences to fell individual cedar trees, which are pit-sawn on site and planks are transported down the mountain on the heads of porters. This system has proved difficult to control and unfortunately some of the 88

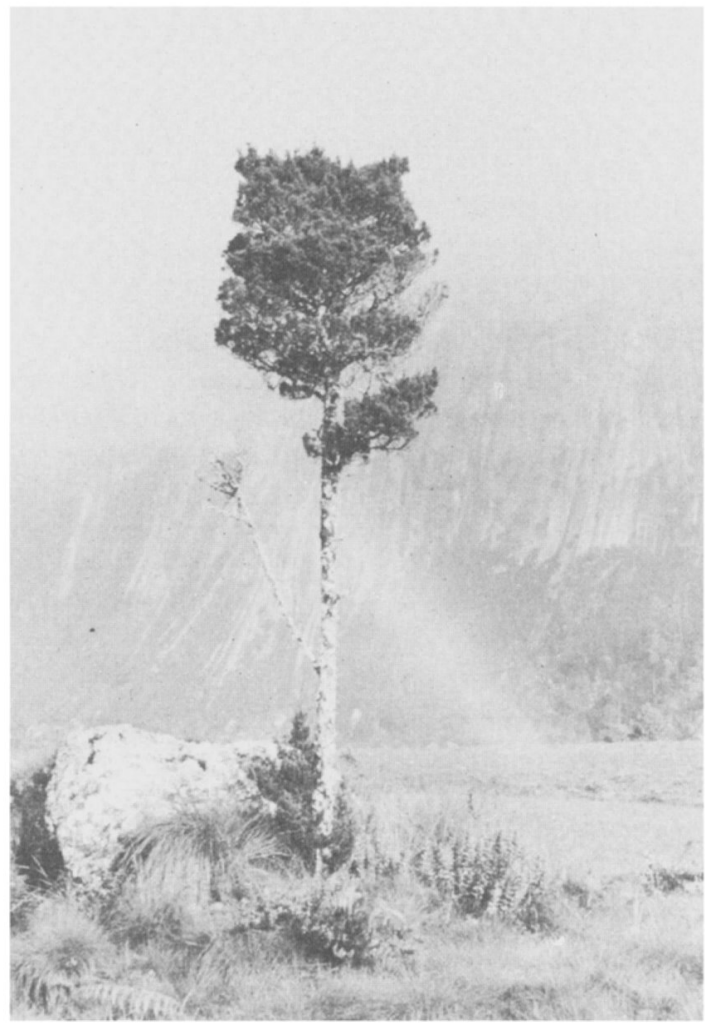

more accessible stands have been degraded by over-cutting. In 1981, the Forestry Department introduced restrictions to conserve the remaining cedar; only dead trees may be felled and the Oryx Vol $19 \mathrm{No} 2$ 
Right: Cedar stand destroyed by fire (Ian Edwards).

Below: Plateau on Mulanje Mountain, showing forest in sheltered hollows (Ian Edwards).

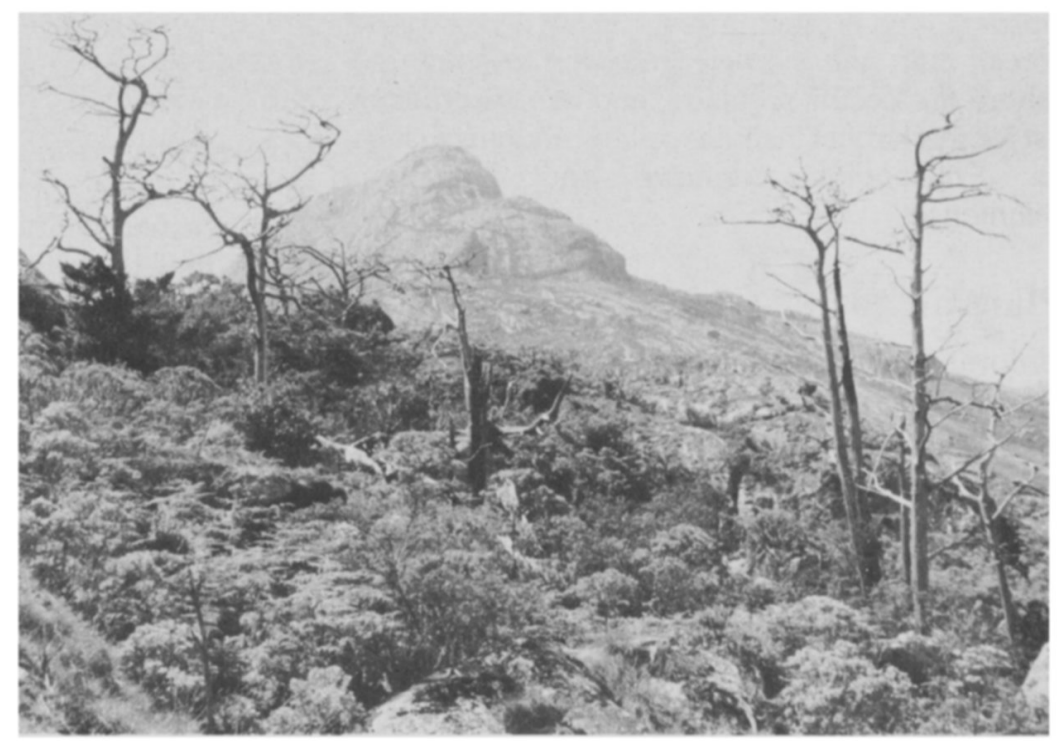

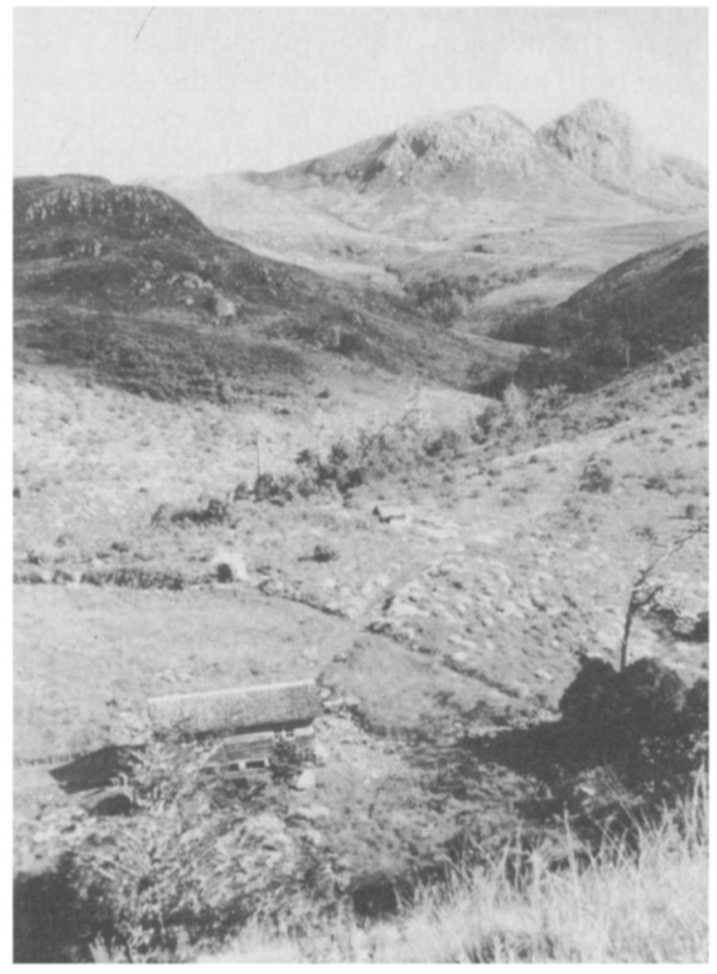

cutting and handling of timber is now undertaken by the Department's own staff.

The most serious threat to the cedar forests is fire.
Although in the original extensive forests the occasional lightning fire probably had an important rejuvenating role in over-mature stands (Chapman and White, 1970), the small size of the present relic stands makes them highly vulnerable to fire damage. Unfortunately some unscrupulous woodcutters may have seen 'accidental' fires as an opportunity of increasing the quantity of dead trees available for felling and there is a suspicion that some burns may have been deliberate arson. This malpractice should cease now that the Forestry Department has taken control of all felling operations.

In older stands the scattered cedars that emerge above a canopy of broadleaved trees will not be replaced, as regeneration beneath the dense shade is impossible. Local extinction of the cedar is not a serious concern as long as young cedar becomes established in open areas outside the present forest limits. Gradual recolonisation of the grassland surrounding some of the forest patches has been occurring since fire protection measures were introduced in 1950. Young cedar trees and other pioneer species, including the giant heath Philippia benguelensis, Buddleja salviifolia and Myrica pilulifera, form a shrubby thicket on the margins of the forest, representing the first stage in a succession to closed forest. These shrubby 
borders give a much more 'natural' edge to the forest than the narrow transition zone found where fire occurs regularly, and the long species list for this habitat includes several endemics, such as Phyllanthus confusus and Geranium mlanjense.

\section{Plant invaders}

Unfortunately in recent years a new problem has arisen, which threatens to interfere with the reestablishment of forest on the Mulanje plateaux. Not content with the rich indigenous flora, man has been introducing alien plants to Mulanje for about 80 years. Two of these foreign invaders, Himalayan raspberry Rubus ellipticus, and a Mexican pine Pinus patula, are rapidly becoming a serious threat to the survival of natural vegetation in areas undergoing forest succession (Edwards, 1982).

The raspberry was the first of these to be introduced, sometime before 1929 . It produces abundant sweet-tasting fruits and it is uncertain whether the original introduction was the result of deliberate planting or migrant birds carrying seed from Zomba, about $70 \mathrm{~km}$ away, where it was established much earlier. For many years it appears to have been relatively unimportant, being confined to forest clearings and edges, but in recent years it has responded to fire protection by invading areas of natural regeneration bordering forest patches. The seed is dispersed by birds, but once established it spreads rapidly by vegetative means, eventually forming impenetrable thickets in which few native species can survive.

Pinus patula was first planted on Mulanje in 1946 on former grassland sites, on the north-western and north-eastern plateaux. The original aim was to underplant with Mulanje cedar as soon as the pines provided sufficient protection from frost, but unfortunately this was never carried out and the plantations were left to reach maturity. The two plantation areas acted as centres for the spread of pine and naturalised trees, originating from wind-blown seed, now occur on five of the six major plateaux. Dense natural regeneration of pine occurs within about $1 \mathrm{~km}$ of the plantations but individual trees, many already producing viable seed, can be found more than $8 \mathrm{~km}$ from 90 the original plantings. These isolated trees will provide foci for further spread and so the process can be expected to accelerate.

In some places $P$ inus patula regeneration appears to be in direct competition with Mulanje cedar. This is especially noticeable in areas of forest or scrub that have been accidentally burnt. Pinus patula trees scorched by the fire release the accumulated seed from several years' cones and the pine seedlings rapidly outgrow any cedar seedlings that may have germinated on the bare ground.

\section{Future prospects}

Many of the endemic plants on Mulanje probably owe their survival to the effective fire control policy instituted by the Foresty Department, although this has been largely incidental, as the main concern has been to protect valuable cedar trees rather than the montane vegetation per se. The recent invasion of alien plants presents a new threat both to the cedar stands and the associated flora, but the Department has the resources to meet this new challenge and technical advice is available from South Africa where there is considerable experience in controlling plant invaders. It is imperative, however, that action is taken soon in order to contain the problem at a relatively early stage. The future of a unique area of outstanding natural beauty and botanical interest is at stake.

\section{References}

Carruthers, W. 1894. Introduction to the plants of Milanii, Nyasaland collected by Mr Alexander Whyte FLS. Trans. Linn. Soc. Lond. (Bot.) 4, 1-4.

Chapman, J.D. 1961. Some notes on the taxonomy, distribution, ecology and economic importance of Widdringtonia with particular reference to $W$. whytei. Kirkia, 1, 138154.

Chapman, J.D. 1962. The Vegetation of the Mlanje Mountains, Nyasaland. Government Printer, Zomba. $78 \mathrm{pp}$.

Chapman, J.D. and White, F. 1970. The Evergreen Forests of Malawi. Commonwealth Forestry Institute, Oxford.

Eastwood, F. 1979. Guide to the Mulanje Massif. Lorton, Johannesburg.

Edwards, 1.D. 1982. Plant invaders on Mulanje mountain, Nyala, 8 (2), 89-94

Wild, H. 1964. The endemic species of the Chimanimani Mountains and their significance (includes a list of Mulanje endemics). Kirkia, 4, 125-159.

Ian Edwards, Royal Botanic Garden, Edinburgh EH3 5LR, UK.

Oryx Vol 19 No 2 